\title{
Biological health or lived health: which predicts self-reported general health better?
}

Cristina Bostan ${ }^{1,2^{*}}$, Cornelia Oberhauser ${ }^{3}$, Gerold Stucki ${ }^{1,2}$, Jerome Bickenbach ${ }^{1,2}$ and Alarcos Cieza $a^{2,3,4}$

\begin{abstract}
Background: Lived health is a person's level of functioning in his or her current environment and depends both on the person's environment and biological health. Our study addresses the question whether biological health or lived health is more predictive of self-reported general health (SRGH).

Methods: This is a psychometric study using cross-sectional data from the Spanish Survey on Disability, Independence and Dependency Situation. Data was collected from 17,739 people in the community and 9,707 from an institutionalized population. The following analysis steps were performed: (1) a biological health and a lived health score were calculated for each person by constructing a biological health scale and a lived health scale using Samejima's Graded Response Model; and (2) variable importance measures were calculated for each study population using Random Forest, with SRGH as the dependent variable and the biological health and the lived health scores as independent variables.
\end{abstract}

Results: The levels of biological health were higher for the community-dwelling population than for the institutionalized population. When technical assistance, personal assistance or both were received, the difference in lived health between the community-dwelling population and institutionalized population was smaller. According to Random Forest's variable importance measures, for both study populations, lived health is a more important predictor of SRGH than biological health.

Conclusions: In general, people base their evaluation of their own health on their lived health experience rather than their experience of biological health. This study also sheds light on the challenges of assessing biological health and lived health at the general population level.

Keywords: Self-reported general health, Biological health, Lived health, Graded Response Model, Random Forest, Spain

\section{Background}

Self-reported general health (SRGH) is the most widely used measure of health in both population and clinical health surveys and the most frequent tool for health comparisons between populations. A Medline literature search showed that in the year 2002, 1,991 scientific papers were published using this question [1]. Most of these studies relied on the standard 'In general, how would you rate your health?' question answered on a five-point Likert-type scale: very bad, bad, fair, good, very good, or poor, fair, good, very good, excellent. This question is also included

\footnotetext{
* Correspondence: cristina.bostan@paraplegie.ch

'Department of Health Sciences and Health Policy, University of Lucerne, Lucerne, Switzerland

${ }^{2}$ Swiss Paraplegic Research, Nottwil, Switzerland

Full list of author information is available at the end of the article
}

in widely-used questionnaires, such as the Short-Form 36 [2] and the European Organization for Research and Treatment of Cancer Quality of Life Questionnaire [3].

The studies using SRGH usually belong to one of two types: SRGH is used either as a predictor of specific health outcomes, such as mortality $[4,5]$, social-psychological well-being [6,7], morbidity [8,9] and health care utilisation [10], or as an outcome of other factors such as medical diagnoses, physical symptoms and functioning [11], social role activities, social relationships [12] and emotional factors [13].

SRGH is not, however, an approach to measuring health that fits all purposes. Salomon et al. [14] claim that SRGH may not be suitable for tracking changes in

\section{Biomed Central}

(c) 2014 Bostan et al.; licensee BioMed Central Ltd. This is an Open Access article distributed under the terms of the Creative Commons Attribution License (http://creativecommons.org/licenses/by/2.0), which permits unrestricted use, distribution, and reproduction in any medium, provided the original work is properly credited. 
population health over time and for comparing the level of health of subpopulations.

We claim in this paper that one reason to question the validity of SRGH for tracking health over time and for cross-population comparability involves the different meanings of health that respondents have in mind when answering the SRGH question.

To test what respondents have in mind when answering the SRGH question, qualitative studies are a good place to begin. These studies scrutinize what respondents are thinking about when answering. Some of these studies have already shown that SRGH is a multidimensional construct and that the perception of health is determined not only by the presence or the absence of health problems (that is, biological health), but also by one or more of the following factors: (1) functional factors - the extent to which people are able to perform actions and tasks; (2) coping factors - the person's level of adaptability, or his or her attitudes towards the health condition, and (3) wellbeing factors - their emotions or feelings [15]. These qualitative studies also suggest that it is very important to anchor the assessment of SRGH to age, gender and time $[15,16]$.

Bearing in mind the value of these studies, the question we wish to answer in this investigation is whether we can psychometrically study what respondents have in mind when answering the SRGH question. To address this question we will use the conceptual basis of the International Classification of Functioning, Disability and Health (ICF) of the World Health Organization (WHO) [17]. According to the ICF model the construct of capacity reflects the intrinsic features of a person to do an action or execute a task independent of the positive or negative influence of the person's physical, attitudinal or social environment. The construct of performance, on the other hand, refers to health in terms of what one's level of capacity in different functioning domains allows us to do in life, taking full account of the impact, positive or negative of one's environment, such as the assistive devices one may use. Health in the sense of capacity is what we mean by 'biological health' and performance is what we mean by 'lived health'. The ICF provides the best framework to describe and measure people's limitations and restrictions and was explicitly not intended to measure quality of life understood as how people feel about these limitations and restrictions.

For this investigation, we selected a population-based study, namely the 2008 Spanish National Disability Survey. We selected this study because it captured both the concepts of biological health and lived health, making it possible for us answer the question whether SRGH is more related to one or the other. The questionnaires used for this survey contained the SRGH question as well as questions about the extent of problems in different domains of functioning, with and without assistive devices or personal assistance. We believe that the extent of problems in domains of functioning without any aids or personal assistance captures biological health, whereas questions about the extent of problems in the same domains but taking into consideration personal or technical assistance addresses the concept of lived health. The aim of this study is, again, to determine whether biological health or lived health is more predictive of SRGH.

\section{Methods}

\section{Study design and participants}

This is a psychometric study using cross-sectional data from the Spanish National Disability Survey from 2008 (Survey on Disabilities, Independence and Dependence Situations - EDAD). This survey included two residencebased population samples, one community-dwelling and the other institutionalized. The 2008 EDAD design has been described previously [18]. Data was only collected for people who fulfilled the disability criterion of having important limitations to carrying out everyday activities that have lasted, or are expected to last, more than one year, and whose origin is an impairment in one of the following eight domains: seeing, hearing, communication, learning and application of knowledge and development of tasks, mobility, self-care, home life, interactions and interpersonal relationships.

\section{Variables}

Forty-two questions were used to assess the level of difficulty in carrying out activities without any technical aid or personal assistance. In our judgment, these are questions about a person's biological health. Thirty-one questions assessing the level of difficulty in most of the same activities but taking into account any kind of technical aid or personal assistance were also asked. These we judged to be lived health questions. The ordinal scale used to assess the limitation level consisted of the following response options: $1=$ Without difficulty or with little difficulty; $2=$ With moderate difficulty; $3=$ With severe difficulty and $4=$ Cannot carry out the activity.

When people did not use technical assistance or have personal assistance, only the question about the level of difficulty 'without' was asked. Additional questions about medical conditions, diagnosis, professional life, education, discrimination, social contacts, accessibility and main caregivers were also asked. The SRGH level was collected using the five point scale, with response options: very bad, bad, fair, good, very good.

\section{Data analysis}

The questions referring to vision and hearing were not considered because no differentiation was made between 
with and without assistive devices or personal assistance. Furthermore, only people that had a difficulty in at least one of the remaining biological health questions were included in the analyses. As a result, 17,739 people from the community-dwelling and 9,707 from the institutionalized population were kept in the analyses.

We used descriptive statistics to present the characteristics of both study populations, taking sampling weights into account. The response options 'With moderate difficulty' and 'With severe difficulty' in both biological health and lived health questions showed a low frequency. Thus, we collapsed them into a single option called 'with moderate/severe difficulty'.

To answer the question whether biological health or lived health is more predictive of SRGH, we (1) calculated a biological health and a lived health score for each person by constructing a biological health scale (BHS) and a lived health scale (LHS) using the Item Response Theory (IRT) Model called Samejima's Graded Response Model (GRM); and (2) calculated the variable importance measures using Random Forest with SRGH as the dependent variable and the biological health score and lived health score as independent variables.

For step one, three specific steps were followed:

a) We evaluated the assumptions of Item Response Theory (IRT) - unidimensionality, local independency and monotonicity - separately for biological health and lived health questions to find out whether IRT could be used for our data. Unidimensionality was examined with bifactor analysis with the analytic bifactor rotations $[19,20]$. Local independency was tested by examining the residual correlations among questions in one-factor model confirmatory factor analysis [21]. We estimated GRM with and without the flagged local dependent questions (residual correlations higher than 0.2) to see if results were robust to question dependencies [22]. Monotonicity was studied by examining graphs of the question mean scores conditional on 'rest-scores' (i.e. total raw scale score minus the question score). Questions that failed one of these three assumptions were not considered in the final model [23].

b) Biological health questions and lived health questions that satisfied the IRT assumptions were used to create a BHS and a LHS using GRM [24].

c) Biological health questions and lived health questions were tested for differential item functioning (DIF) for study population (institutionalized and community-dwelling), gender (male and female), age groups ( $\leq 65$ and $>65$ ) and reported number of health conditions groups $(0,1-2$ and >2) using iterative hybrid ordinal logistic regression with change in McFadden's pseudo R-squared measure (above 0.02) as DIF criterion [25,26]. Questions showing DIF were calibrated separately for each of the groups showing DIF and after DIF correction final GRMs were calculated. Based on the resulting biological health question parameters and lived health question parameters, a summary score of biological health and a summary score of lived health for each of the individuals in the sample were calculated. For a more intuitive summary score for the biological health or lived health of individuals, we transformed the resulting scores into more meaningful values, ranging from 0 (best biological health or lived health) to 100 (worst biological health or lived health). For both study populations, the relation between biological health and lived health was studied using the Pearson correlation analysis.

For step two, for each of the community-dwelling and institutionalized data sets, we (1) studied the association between biological health scores, lived health scores and SRGH by using Spearman correlation coefficient $\left(r_{S}\right)$ and box-plots which displayed the distribution of biological health scores and lived health scores in each of the five SRGH response options; and (2) compared the importance value of the biological health score with that of the lived health score obtained from Random Forest regression with 1000 trees and mtry $=2$, where 2 means the number of randomly preselected independent variables, which in Random Forest are called split variables. The Random Forest regression provides an improved prediction accuracy compared to other regression techniques (e.g. logistic or linear regression) because it deals with the collinearity and the main and interaction effects of independent variables. The variable importance measure is the average of the frequency with which the independent variables (biological health and lived health) appear in all 1000 trees calculated to predict the dependent variable (SRGH) over all 1000 trees. It takes values from 0 to 1 , the higher the value, the better the prediction of SRGH. The permutation importance was computed with the conditional permutation scheme proposed by Strobl and colleagues, which controls for the correlation of the predictor variables [27].

All the analyses were performed with $\mathrm{R}$ version 2.15.1 [28].

\section{Results}

Characteristics of both study populations are presented in Table 1. In both study populations around 60\% were female. Most of the institutionalized people were aged more than 65 years (82\%). The percentage of respondents reporting very good or good health is 38.2 in the institutionalized and 20.7 in the community-dwelling population. 
Table 1 Characteristics of institutionalized and community-dwelling population

\begin{tabular}{|c|c|c|}
\hline & $\begin{array}{c}\text { Institutionalized } \\
\text { population } \\
(\mathrm{N}=9707) \\
\%\end{array}$ & $\begin{array}{c}\text { Community-dwelling } \\
\text { population } \\
(\mathrm{N}=17739) \\
\%\end{array}$ \\
\hline \multicolumn{3}{|l|}{ Gender } \\
\hline Female & 65.5 & 63.3 \\
\hline \multicolumn{3}{|l|}{ Age, years } \\
\hline Old $(>65)$ & 82.0 & 58.5 \\
\hline \multicolumn{3}{|l|}{ Education } \\
\hline No school & 21.8 & 11.9 \\
\hline Primary-school-incomplete & 45.3 & 35.6 \\
\hline Primary-school-complete & 23.4 & 28.8 \\
\hline Secondary school first step & 3.0 & 9.3 \\
\hline Secondary school finished & 3.1 & 5.3 \\
\hline Professional school medium & 1.3 & 2.8 \\
\hline Professional school superior & 0.5 & 1.7 \\
\hline University & 1.5 & 4.6 \\
\hline \multicolumn{3}{|l|}{ SRGH } \\
\hline SRGH: very good & 3.0 & 1.5 \\
\hline SRGH: good & 35.2 & 19.2 \\
\hline SRGH: fair & 37.1 & 44.9 \\
\hline SRGH: bad & 18.8 & 26.5 \\
\hline SRGH: very bad & 5.9 & 7.9 \\
\hline \multicolumn{3}{|l|}{ Number of health conditions ${ }^{a}$} \\
\hline No health condition & 12.3 & 12.4 \\
\hline One or two health conditions & 68.6 & 50.1 \\
\hline $\begin{array}{l}\text { Three or more than three } \\
\text { health conditions }\end{array}$ & 19.1 & 37.5 \\
\hline
\end{tabular}

All data are population weighted.

SRGH = Self-reported general health.

${ }^{a}$ The health conditions were: Spinal cord injury, Parkinson's, Lateral sclerosis, Multiple sclerosis, Agenesis/Amputation, Laryngectomy, Arthritis, Rheumatoid arthritis or Ankylosing spondylitis, Muscular dystrophy, Spina bifida/

hydrocephaly, Myocardial infarction or Ischaemic cardiopathy, Cerebrovascular accidents, Down's Syndrome, Autism and other disorders associated with autism, Cerebral paralysis, Acquired brain damage, Senile Dementia of the Alzheimer Type, Other types of dementia, Schizophrenia, Depression, Bipolar disorder, Pigmentary retinosis, Myopia magna, Senile macular degeneration, Diabetic retinopathy, Glaucoma, Cataract, HIV/AIDS, Rare illnesses, Cancer (only for community-dwelling population).

Table 2 shows the biological health and lived health questions considered for BHS and LHS, respectively.

\section{Biological health and lived health scores IRT Assumptions}

Unidimensionality. For both BHS and LHS the bifactor analyses supported the assumption of a strong general factor, with all questions loading highly on the general factor. However, questions from the mobility domain of LHS and questions from the communication domain and learning and application of knowledge and development of tasks domain of LHS loaded higher on their respective group factors than on the general factor. We decided to proceed with unidimensional BHS and unidimensional LHS, since these domains are contributing to biological health and lived health, respectively. We checked our decision by estimating the GRMs both with and without mobility for BHS and communication and learning and application of knowledge and development of tasks for LHS and analyzed the correlation between the item thresholds for the two models each. The results showed that our decision did not affect the results.

Local independency. While the examination of the residual correlations of biological health questions indicated violation of local independency in five groups of questions, the results for lived health questions revealed violation in six. Table 2 shows the local dependent questions as well as the questions considered in the final models.

Monotonicity. The monotonicity IRT assumption was satisfied by most of the biological health and lived health questions, with the exception of the questions: 'With what level of difficulty would you say are you able to carry out activities related to menstrual care?' and 'With what level of difficulty would you say are you able to drive vehicles?'.

Differential item functioning. Table 3 presents the biological health and lived health questions included in the BHS and LHS respectively and their parameter estimates (discrimination and threshold parameters) for the final GRM models. While for BHS 6 questions showed DIF for study population and 11 questions for age groups, for LHS 7 questions showed DIF for study population, and 4 for age groups. All questions of the BHS and of the LHS were free of DIF for gender and number of health conditions.

\section{Biological health scale and lived health scale}

The most discriminating biological health question was 'initiate and maintain intimate or sexual relations' in the community-dwelling old age group (with a discrimination of 4.97). This means that this question differentiates well between people with high and lower difficulties in biological health in the old age group. The least discriminating question was 'walk or move outside the home' (with a discrimination of 0.62). For LHS, the most discriminating question was 'carry out housework' (with a discrimination of 4.25); the least discriminating was 'speak intelligibly or utter coherent phrases' in the community-dwelling young-age group (with a discrimination of 0.91). While the question for which only those individuals in the worst biological health are expected to 
Table 2 Biological health and lived health questions initially considered for the GRM models for each study population: institutionalized and community-dwelling population

\begin{tabular}{|c|c|c|c|c|c|c|c|c|c|c|}
\hline \multirow{3}{*}{ Questions } & \multicolumn{5}{|c|}{ Biological health scale } & \multicolumn{5}{|c|}{ Lived health scale } \\
\hline & \multirow[t]{2}{*}{ Variable } & \multicolumn{2}{|c|}{$\begin{array}{l}\text { Institutionalized } \\
\text { population }\end{array}$} & \multicolumn{2}{|c|}{$\begin{array}{c}\text { Community-dwelling } \\
\text { population }\end{array}$} & \multirow[t]{2}{*}{ Variable } & \multicolumn{2}{|c|}{$\begin{array}{l}\text { Institutionalized } \\
\text { population }\end{array}$} & \multicolumn{2}{|c|}{$\begin{array}{c}\text { Community-dwelling } \\
\text { population }\end{array}$} \\
\hline & & $\mathrm{N}$ & \%difficulty & $\mathrm{N}$ & \%difficulty & & $\mathrm{N}$ & \%difficulty & $\mathbf{N}$ & \%difficulty \\
\hline
\end{tabular}

\section{Communication}

With what level of difficulty would you say you are able to...

Speak intelligibly or utter coherent phrases?

Understand what other persons say to you?

Understand and express yourself in writing?

Understand and express yourself via gestures, symbols, illustrations or sounds?

Hold a dialogue and exchange ideas with one or more persons?

Use the telephone or other devices or communication techniques?

Learning and application of knowledge and development of tasks

With what level of difficulty are you able to. .

Hold a gaze or pay

attention when

listening?

Learn to perform simple tasks?

Perform simple tasks?

Perform complex tasks?

$$
\text { COM_8_2 } 9702
$$$$
36.4
$$$$
\text { COM_9 } 29703
$$$$
35.6
$$$$
\text { COM_10_2 } 9687
$$

COM_11_2 9703

$$
34.8
$$

15048

15912

14.8

COM_8_3b ${ }^{6} \quad 9696$

36.1

15912

14.7

COM_12_2 9698

41.6

15899

14.8

COM_13_2 9678

51.4

16605

18.0

COM_13_3b ${ }^{6} 9666$

45.4

16578

15.8

Mobility

With what level of difficulty are you able to..

Change posture?

Keep the body in the same position?

Walk and move around the home?

Walk or move outside the home?

$\begin{array}{lllll}\text { APR_14_2 } & 9705 & 29.2 & 15793 & 10.2 \\ & & & & \\ \text { APR_15_2 } & 9665 & 41.2 & 16657 & 14.9 \\ & & & & \\ \text { APR_16_2 } & 9707 & 34.0 & 16068 & 11.4 \\ \text { APR_17_2 } & 9707 & 49.7 & 17229 & 17.6\end{array}$

\begin{tabular}{|c|c|c|c|c|c|c|c|c|}
\hline MOV_18_2 ${ }^{1}$ & 9698 & 45.9 & 9578 & 64.6 & MOV_18_3b & 9599 & 36.3 & 9527 \\
\hline MOV_19_2 & 9704 & 41.2 & 9923 & 66.1 & MOV_19_3b & 9645 & 33.5 & 9869 \\
\hline MOV_20_2 ${ }^{1}$ & 9705 & 53.4 & 8751 & 61.0 & MOV_20_3b ${ }^{8}$ & 9641 & 40.3 & 8701 \\
\hline MOV_21_2 $2^{2}$ & 9683 & 81.4 & 12919 & 74.3 & MOV_21_3b 9 & 9640 & 62.5 & 12846 \\
\hline
\end{tabular}

$\begin{array}{lllll}\text { APR_16_3b } & 9680 & 29.9 & 16054 & 10.0 \\ \text { APR_17_3b } & 9676 & 44.2 & 17208 & 15.2\end{array}$


Table 2 Biological health and lived health questions initially considered for the GRM models for each study population: institutionalized and community-dwelling population (Continued)

\begin{tabular}{|c|c|c|c|c|c|c|c|c|c|c|}
\hline $\begin{array}{l}\text { Get around via } \\
\text { passenger transport? }\end{array}$ & MOV_22_2 $2^{2}$ & 9693 & 85.7 & 12156 & 73.2 & MOV_22_3b9 & 9649 & 68.5 & 12079 & 63.4 \\
\hline Drive vehicles? & MOV_23_2 $2^{2}$ & 3653 & 82.7 & 4378 & 55.5 & MOV_23_3b & 3648 & 82.1 & 4378 & 51.5 \\
\hline Lift or carry objects? & MOV_24_2 $2^{3}$ & 9705 & 52.3 & 11259 & 70.6 & MOV_24_3b ${ }^{10}$ & 9684 & 47.3 & 11215 & 63.7 \\
\hline $\begin{array}{l}\text { Handle and move } \\
\text { objects? }\end{array}$ & MOV_25_2 $2^{3}$ & 9705 & 36.0 & 9056 & 63.2 & MOV_25_3b $b^{10}$ & 9685 & 32.5 & 9022 & 57.1 \\
\hline $\begin{array}{l}\text { Lift or carry small } \\
\text { objects? }\end{array}$ & MOV_26_2 $2^{3}$ & 9704 & 38.6 & 7840 & 56.8 & MOV_26_3b ${ }^{10}$ & 9682 & 34.5 & 7816 & 51.8 \\
\hline \multicolumn{11}{|l|}{ Self-care } \\
\hline \multicolumn{11}{|l|}{$\begin{array}{l}\text { With what level of } \\
\text { difficulty would you } \\
\text { say are you able to... }\end{array}$} \\
\hline $\begin{array}{l}\text { Wash or dry different } \\
\text { body parts? }\end{array}$ & AUT_27_2 & 9702 & 77.6 & 14557 & 49.8 & AUT_27_3b & 9600 & 57.1 & 14491 & 40.0 \\
\hline Perform basic grooming? & AUT_28_2 & 9702 & 78.1 & 14249 & 48.9 & AUT_28_3b & 9611 & 58.8 & 14160 & 38.0 \\
\hline $\begin{array}{l}\text { Carry out activities } \\
\text { related to urination? }\end{array}$ & AUT_29_2 & 9704 & 52.6 & 11346 & 36.4 & AUT_29_3b & 9657 & 41.6 & 11295 & 30.4 \\
\hline $\begin{array}{l}\text { Carry out activities } \\
\text { related to defecation? }\end{array}$ & AUT_30_2 & 9701 & 48.3 & 9979 & 28.0 & AUT_30_3b & 9663 & 38.8 & 9946 & 24.6 \\
\hline $\begin{array}{l}\text { Carry out activities } \\
\text { related to menstrual } \\
\text { care? }\end{array}$ & AUT_31_2 & 680 & 56.6 & 1501 & 12.1 & AUT_31_3b & 674 & 38.0 & 1501 & 9.6 \\
\hline Dress or undress? & AUT_32_2 & 9706 & 59.5 & 13035 & 44.2 & AUT_32_3b & 9648 & 45.3 & 12975 & 35.2 \\
\hline Eat and drink? & AUT_33_2 & 9704 & 31.0 & 9301 & 22.9 & AUT_33_3b & 9690 & 23.8 & 9269 & 18.4 \\
\hline $\begin{array}{l}\text { Follow medical } \\
\text { prescriptions? }\end{array}$ & AUT_34_2 & 9693 & 69.2 & 12085 & 40.2 & AUT_34_3b & 9627 & 44.1 & 12032 & 24.3 \\
\hline $\begin{array}{l}\text { Avoid dangerous } \\
\text { situations? }\end{array}$ & AUT_35_2 & 9667 & 62.4 & 10987 & 34.4 & AUT_35_3b & 9621 & 51.9 & 10951 & 27.1 \\
\hline
\end{tabular}

\section{Home Life}

With what level of difficulty would you say are you able to...

Do shopping?

VDOM $362^{4}-9675$

VDOM_36_3b ${ }^{11} 2355$

Prepare meals? VDOM_37_24 9243

Interaction and interpersonal relations

With what level of difficulty would you say are you able to...

Show to other persons affection, respect or transmit feelings?

Relate to strangers?

INTER_39_2 $\mathbf{2}^{\mathbf{5}} 970$

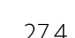

9.4

Initiate and maintain

INTER_40_2 9700

43.6

16666

14.2

relations with

subordinates, peers

INTER_41_25 9701

$26.7 \quad 16222$

12.0 
Table 2 Biological health and lived health questions initially considered for the GRM models for each study population: institutionalized and community-dwelling population (Continued)

\begin{tabular}{lccccc}
\hline $\begin{array}{l}\text { Initiate and maintain } \\
\text { relations with friends, } \\
\text { neighbours, } \\
\text { acquaintances or } \\
\text { colleagues? }\end{array}$ & INTER_42_2 & 9704 & 33.5 & 16264 & 12.3 \\
$\begin{array}{l}\text { Initiate and maintain } \\
\text { family relations? }\end{array}$ & INTER_43_2 & 9694 & 26.9 & 16281 & 12.5 \\
$\begin{array}{l}\text { Initiate and maintain } \\
\text { intimate or sexual }\end{array}$ & INTER_44_2 & 9647 & 67.0 & 16660 & 14.6 \\
relations? & & & & & \\
\end{tabular}

Local dependent variables are marked with the same number. The questions considered in the final model are marked in bold. All data are population weighted.

have median difficulties is 'hold a gaze or pay attention when listening' (with a threshold of 2.55 on the logit scale), the question for which individuals in the worst lived health are expected to have high difficulties is 'speak intelligibly or utter coherent phrases' in the community-dwelling young-age group (with a threshold of 3.80).

On a scale from 0 (best biological health) to 100 (worst biological health), the levels of biological health are higher for community-dwelling (mean $=31.07$, standard deviation $=21.22$, range $=[0 ; 98.96])$ than for institutionalized population $($ mean $=48.86$, standard deviation $=23.54$, range $=[0 ; 100])$. When technical assistance, personal assistance or both was received, the difference between community-dwelling $($ mean $=31.94$, standard deviation $=$ 20.72 , range $=[0 ; 100])$ and institutionalized populations $($ mean $=36.75$, standard deviation $=22.69$, range $=[2.09$; 93.22]) was smaller. The biological health score and lived health score are not comparable since they were calculated based on two separate sets of questions.

For both study populations the Pearson correlation between biological health and lived health was high: 0.79 for community-dwelling population and 0.85 for institutionalized population.

\section{Conditional permutation importance of biological health and lived health scores}

For both community-dwelling and institutionalized populations the association between SRGH and lived health scores (community dwelling: $r_{S}=0.33$, institutionalized: $\left.r_{S}=0.36\right)$ was higher than the association between SRGH and biological health scores (community dwelling: $r_{\mathrm{S}}=$ 0.23 , institutionalized: $\left.r_{S}=0.30\right)$. The relation between SRGH and biological health scores and lived health scores is displayed in Figure 1.

The resulting importance measures of the two predictors (biological health score and lived health score) of SRGH are displayed in Figure 2. For both samples, the lived health score showed the higher variable importance and therefore was a better predictor of SRGH than the biological health score.

\section{Discussion}

Comparing the predictive value for SRGH of biological health and lived health in a psychometric space is the first step towards a true understanding of what people are thinking about when rating their general health. Our study showed that people base their evaluation of their health, not on their biological state, but on their lived experience of their health. This is an important result because it implies that any kind of intervention that targets population health should address, not merely the intrinsic capacity of a person, but also his or her environment.

We are not aware of studies reporting on the comparison of predictive power of biological health and lived health on SRGH. Yet, our finding is similar to, and confirms the Smith et al. [29] conclusion that 'sickness is a social role in addition to biological state' and that SRGH 'is not a continuum of biological states'. As Jylhä [30] suggested, the response to SRGH is influenced not only by 'earlier health experiences, present health conditions', but also by the health-related environment.

Bifactor analyses of biological health questions and lived health questions supported the construction of BHS and LHS, in terms of the contribution of questions to a single common dimension. The presence of an underlying factor that links domains of functioning commonly used to operationalize biological health and lived health helped us to quantify both biological and lived health as a single number, which facilitated comparability between people's abilities from the two study populations. Our results with respect to BHS and LHS are also concordant with other findings [31].

The GRM IRT modelling was used to assess the levels of biological health and lived health. The primary advantage of using an IRT model is that it allows for an estimation of biological health and lived health independent of the set of test questions administrated [32]. For BHS, this makes it possible for us to consider questions that addressed domains of functioning that were not addressed by lived health questions.

The different gradients captured in the developed BHS and LHS - study population and age - support the 
Table 3 Biological health and lived health questions included in the single biological health scale and lived health scale and their parameter estimates (discrimination (Discr) and threshold parameters (Thr 1-2)) for the final GRM models

\begin{tabular}{|c|c|c|c|c|c|c|c|c|}
\hline \multirow[b]{2}{*}{ Questions } & \multicolumn{4}{|c|}{ Biological health scale } & \multicolumn{4}{|c|}{ Lived health scale } \\
\hline & Split in & Discr & Thr 1 & Thr 2 & Split in & Discr & Thr 1 & Thr 2 \\
\hline Communication & & & & & & & & \\
\hline
\end{tabular}

With what level of difficulty would you say you are able to...

Speak intelligibly or utter coherent phrases?

\section{Young}

$2.106 \quad 0.690 \quad 1.698$

Speak inteligibly or utter coherent phrases?

Understand what other persons say to you?

Understand and express yourself in writing?

Understand and express yourself via gestures,

symbols, illustrations or sounds?

Hold a dialogue and exchange ideas with one or more persons?

Use the telephone or other devices or communication techniques?

\section{Learning and application of knowledge and development of tasks}

With what level of difficulty are you able to...

Hold a gaze or pay attention when listening?

Learn to perform simple tasks?

Perform simple tasks?

Perform complex tasks?

\section{Mobility}

With what level of difficulty are you able to...

Walk and move around the home?

Walk or move outside the home?

Lift or carry objects?

Handle and move objects?

Lift or carry small objects?

\begin{tabular}{|c|c|c|c|c|c|c|c|}
\hline Institutionalized young & 2.033 & 1.433 & 2.126 & Institutionalized young & 2.904 & 1.025 & 2.172 \\
\hline Institutionalized old & 1.394 & 0.148 & 1.427 & Institutionalized old & 1.957 & 0.523 & 2.191 \\
\hline \multirow[t]{6}{*}{ Community-dwelling } & 1.987 & -0.447 & 1.196 & Community-dwelling & 1.390 & 0.083 & 2.927 \\
\hline & 0.626 & -2.691 & 1.156 & & 1.813 & -0.128 & 2.097 \\
\hline & & & & Institutionalized & 1.938 & 0.309 & 1.005 \\
\hline & & & & Community-dwelling & 1.314 & -0.416 & 1.731 \\
\hline & & & & Institutionalized & 2.436 & 0.800 & 1.535 \\
\hline & & & & Community-dwelling & 1.463 & -0.121 & 2.178 \\
\hline Institutionalized & 1.895 & 0.931 & 1.708 & Institutionalized & 2.407 & 0.721 & 1.576 \\
\hline Community-dwelling & 2.122 & -0.319 & 1.212 & Community-dwelling & 1.631 & -0.034 & 1.914 \\
\hline
\end{tabular}


Table 3 Biological health and lived health questions included in the single biological health scale and lived health scale and their parameter estimates (discrimination (Discr) and threshold parameters (Thr 1-2)) for the final GRM models (Continued)

Self-Care

With what level of difficulty would you say are you able to..

Wash or dry different body parts?

\begin{tabular}{|c|c|c|c|c|c|c|}
\hline Young & 2.590 & 0.019 & 1.040 & 2.760 & 0.197 & 1.695 \\
\hline \multirow[t]{2}{*}{ Old } & 2.475 & -0.549 & 0.908 & & & \\
\hline & 1.922 & -0.375 & 0.994 & 2.325 & 0.159 & 1.597 \\
\hline Institutionalized young & 3.571 & 1.090 & 1.542 & 2.562 & 0.501 & 1.720 \\
\hline Institutionalized old & 1.728 & 0.358 & 1.352 & & & \\
\hline Community-dwelling & 3.129 & -0.169 & 0.893 & & & \\
\hline Young & 2.275 & 0.902 & 1.682 & 2.862 & 0.541 & 1.637 \\
\hline Old & 2.247 & 0.373 & 1.144 & & & \\
\hline Institutionalized young & 3.591 & 0.750 & 1.545 & 3.445 & 0.361 & 1.565 \\
\hline Institutionalized old & 2.057 & 0.161 & 0.923 & & & \\
\hline Community-dwelling & 3.294 & -0.278 & 0.723 & & & \\
\hline Institutionalized & 2.196 & 1.128 & 1.914 & 2.837 & 0.913 & 2.165 \\
\hline \multirow[t]{3}{*}{ Community-dwelling } & 3.140 & -0.043 & 1.439 & & & \\
\hline & 1.789 & -0.220 & 1.875 & 1.967 & 0.521 & 1.648 \\
\hline & 1.957 & 0.113 & 1.457 & 2.664 & 0.290 & 0.955 \\
\hline
\end{tabular}

Follow medical prescriptions?

Avoid dangerous situations?

\section{Home Life}

With what level of difficulty would you say are you able to...

Do shopping?

Prepare meals?

Carry out housework?

Interaction and interpersonal relations

With what level of difficulty would you say are you able to...

Show to others affection, respect or transmit feelings?

Relate to strangers?

Initiate and maintain relations with friends, neighbours, acquaintances or colleagues?

Initiate and maintain intimate or sexual relations?

$\begin{array}{cccc}\text { Young } & 1.820 & 1.224 & 2.325 \\ \text { Old } & 2.374 & 1.423 & 2.221 \\ & 1.837 & 1.026 & 1.969 \\ \text { Young } & 1.865 & 0.952 & 1.825 \\ \text { Old } & 2.917 & 1.202 & 1.806 \\ \text { Institutionalized } & 1.359 & -0.175 & 0.515 \\ \text { Community-dwelling } & 1.920 & 0.654 & 1.325 \\ \begin{array}{c}\text { young } \\ \text { Community-dwelling }\end{array} & 4.970 & 1.151 & 1.295\end{array}$

old

validity of both scales. However, there is a large number of lived health questions showing DIF. One possible explanation is that institutionalized people receive constant support from hospital personal. This is not the case in the community-dwelling population. In fact more than half of the community-dwelling population did not benefit from personal help. For the age groups, the DIF could be explained by the use of a cut-off of 65 years, which was available in both populations and was in line with others studies that showed that SRGH is worse after an age of 65 years in the Spanish population [33].

For both study populations, the Spearman correlation analysis showed that there is a stronger association between lived health and SRGH than between biological health and SRGH. Since correlation analysis is not a full proof of the strength of biological health and lived 

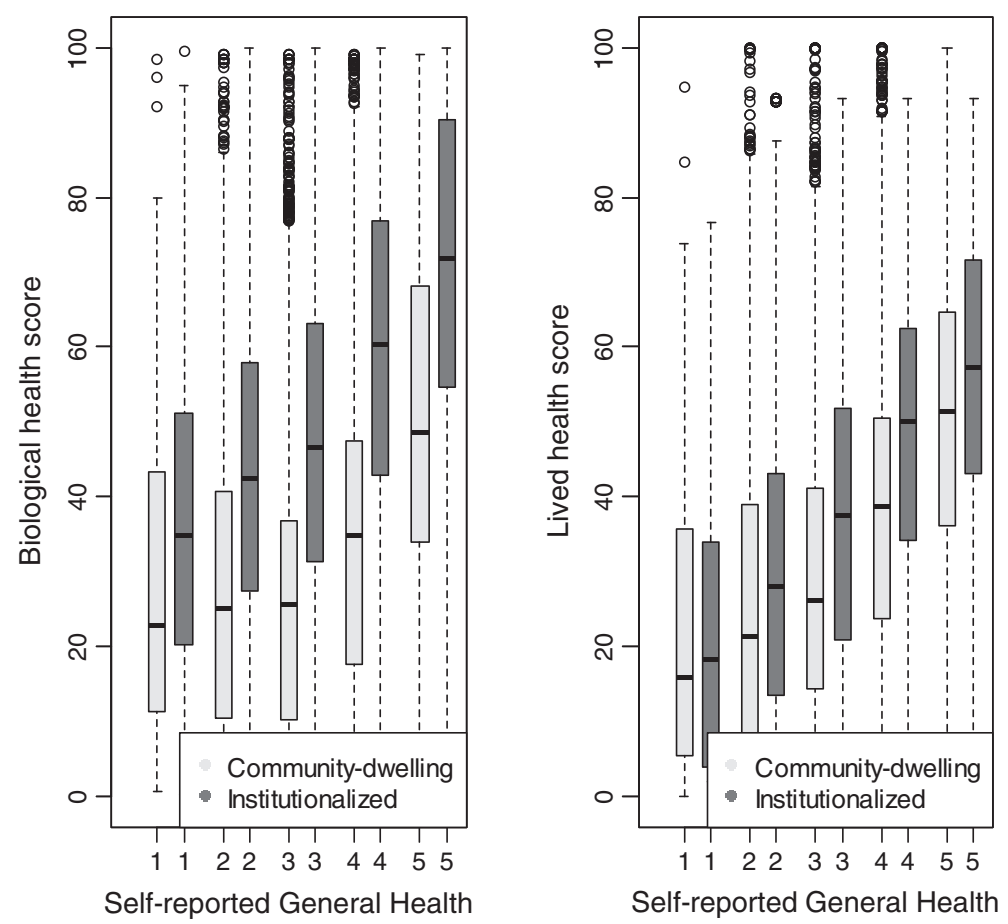

Figure 1 Box-plot showing the distribution of biological health scores and lived health scores in each of the five SRGH response options ( 1 = very good, 2 = good, $3=$ fair, 4 = bad, $5=$ very bad $)$.

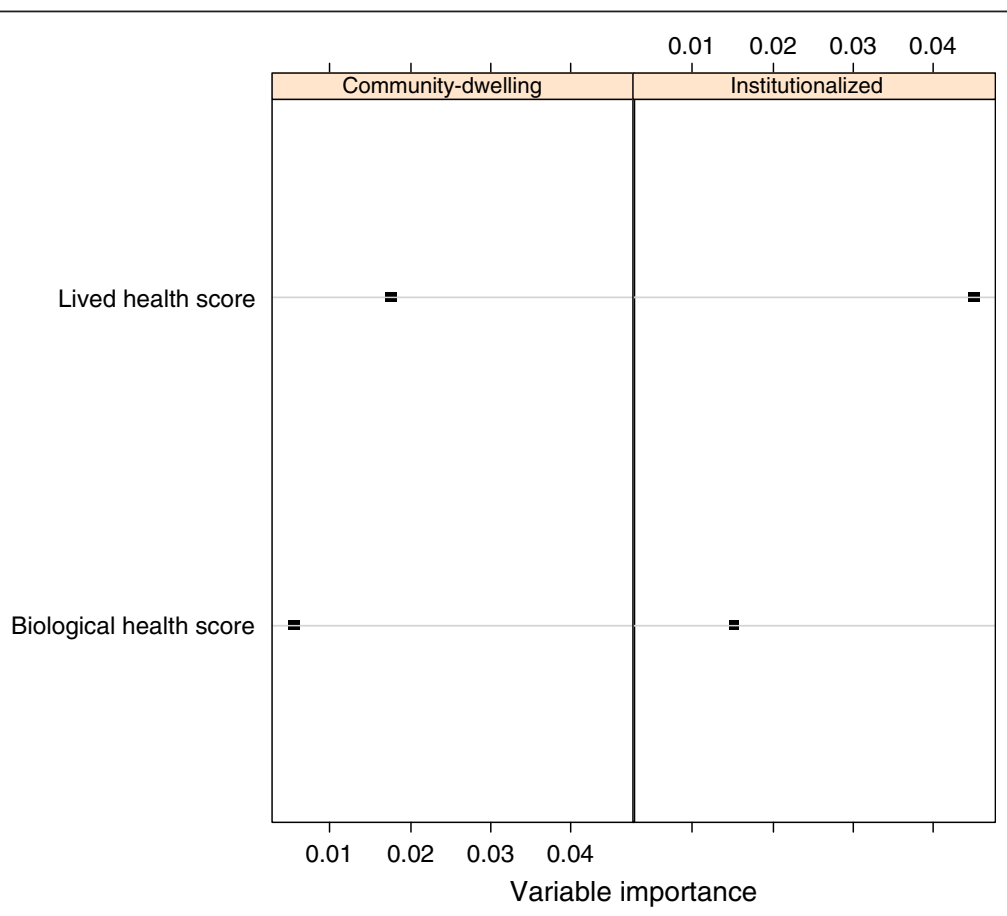

Figure 2 Conditional permutation importance of biological health and lived health scores as predictors of SRGH by study population. The higher the value, the better the prediction of SRGH. 
health to cause the answer to the SRGH, the regression analysis was used. The causal chain results from the correlation analysis: biological health - > lived health -> SRGH. This implies that linear regression with SRGH as a dependent variable and biological health and lived health as independent variables would have a coefficient zero for biological health, i.e. conditional on lived health, biological health is not contributing anything to predict SRGH. The results of qualitative studies showed that some people will disagree that biological health is unimportant to SRGH, therefore we used the optimal solution of overcoming the structural relation between the variables, namely Random Forest regression and the variable importance measures. Certainly, the causal chain indicates that both biological health and lived health are important factors to consider when people rate their health. However, using the Random Forest regression informs us that it is enough to measure lived health for predicting SRGH.

\section{Strengths and limitations}

The most important strength of this study was its large nationally representative Spanish sample. Yet, it is significant that this sample is only representative of persons with limitations in functioning and not the general population. This is because the design of the 2008 EDAD used a representative Spanish sample as starting point but only obtained more detailed information about lived health from the subpopulation with limitations in biological health. Thus, our results are not generalizable to the entire Spanish population. There were additional limitations. First, more aspects of the environment that affect the experience of health in everyday life should be considered in addition to personal support and technical aids. Secondly, an artificial cut-off was set, in the sense that only what was considered larger than or equal to moderate difficulty could be rated as 'moderate', 'severe' or 'cannot carry out the activity'. We had to assume that people answering 'no difficulty' were those who either had no or little difficulty, and in any event did not have a severe enough problem to rate it as moderate. We also had to collapse the response options 'moderate' and 'severe' difficulty because of the skewed distribution towards complete limitation of the response options.

\section{Conclusions}

Our study showed that people base their evaluation of health on their lived health experience rather than their experience of biological health. This result needs to be confirmed and supported by further studies before conclusions can be drawn and practical implications proposed to improve health policy. However, since SRGH can predict the use of health services [34], our study result points to the need on the part of health service personnel and decision makers to consider lived health when they develop and implement health promotion programs or select study outcomes. People with health problems are handed over to health professionals, and this creates an important responsibility. The decisions of health professions should take into account the fact that their patients may be less concerned to know medical facts and more interested in how their health affects everything that they do in their lives. Further research is necessary to determine whether lived health rather that SRGH could be considered when health professionals track health changes over time and for health crosspopulation comparability.

\section{Abbreviations}

SRGH: Self-reported general health; BHS: Biological health scale; LHS: Lived health scale; GRM: Graded Response Model; IRT: Item Response Theory; DIF: Differential item functioning; EDAD: Survey on disabilities, independence and dependence situations.

\section{Competing interests}

The authors declare that they have no competing interests.

\section{Authors' contributions}

$\mathrm{CB}$ and $\mathrm{AC}$ conceived of the study, and its design and drafted the manuscript. CB carried out the statistical analyses. CO made substantial contributions to data analysis. CO, JB and GS critically revised the manuscript in several drafting rounds. All authors read and approved the final manuscript.

\section{Author details}

'Department of Health Sciences and Health Policy, University of Lucerne, Lucerne, Switzerland. ${ }^{2}$ Swiss Paraplegic Research, Nottwil, Switzerland. ${ }^{3}$ Department of Medical Informatics, Biometry and Epidemiology - IBE, Public Health and Health Services Research, Research Unit for Biopsychosocial Health, Ludwig-Maximilians-University (LMU), Munich, Germany. ${ }^{4}$ Faculty of Social and Human Sciences, School of Psychology, University of Southampton, Southampton, UK.

Received: 13 August 2013 Accepted: 13 February 2014 Published: 21 February 2014

\section{References}

1. Mantzavinis GD, Pappas N, Dimoliatis ID, loannidis JP: Multivariate models of self-reported health often neglected essential candidate determinants and methodological issues. J Clin Epidemiol 2005, 58:436-443.

2. Ware JE Jr, Sherbourne CD: The MOS 36-item short-form health survey (SF-36). I. Conceptual framework and item selection. Med Care 1992, 30:473-483.

3. Aaronson NK, Bullinger M, Ahmedzai S: A modular approach to quality-oflife assessment in cancer clinical trials. Recent Results Cancer Res 1988, 111:231-249.

4. Idler EL, Benyamini Y: Self-rated health and mortality: a review of twentyseven community studies. J Health Soc Behav 1997, 38:21-37.

5. Benjamini $Y$, Idler EL: Community studies reporting associations between self-rated health and mortality - additional studies, 1995 to 1998. Res Aging 1999, 21:392-401.

6. Hillen T, Schaub R, Hiestermann A, Kirschner W, Robra BP: Self rating of health is associated with stressful life events, social support and residency in East and West Berlin shortly after the fall of the wall. J Epidemiol Community Health 2000, 54:575-580.

7. Mulsant BH, Ganguli M, Seaberg EC: The relationship between self-rated health and depressive symptoms in an epidemiological sample of community-dwelling older adults. J Am Geriatr Soc 1997, 45:954-958.

8. Dominick KL, Ahern FM, Gold CH, Heller DA: Relationship of health-related quality of life to health care utilization and mortality among older adults. Aging Clin Exp Res 2002, 14:499-508. 
9. Idler EL, Kasl S: Health perceptions and survival: do global evaluations of health status really predict mortality? J Gerontol 1991, 46:S55-S65.

10. Kennedy BS, KasI SV, Vaccarino V: Repeated hospitalizations and self-rated health among the elderly: a multivariate failure time analysis. Am J Epidemiol 2001, 153:232-241.

11. Perruccio AV, Power JD, Badley EM: Arthritis onset and worsening self-rated health: a longitudinal evaluation of the role of pain and activity limitations. Arthritis Rheum 2005, 53:571-577.

12. Gilmour $\mathrm{H}$ : Social participation and the health and well-being of Canadian seniors. Health Rep 2012, 23:23-32.

13. von dem Knesebeck O, Geyer S: Emotional support, education and selfrated health in 22 European countries. BMC Public Health 2007, 7:272.

14. Salomon JA, Nordhagen S, Oza S, Murray CJ: Are Americans feeling less healthy? The puzzle of trends in self-rated health. Am J Epidemiol 2009, 170:343-351.

15. Simon JG, De Boer JB, Joung IM, Bosma H, Mackenbach JP: How is your health in general? A qualitative study on self-assessed health. Eur J Public Health 2005, 15:200-208.

16. Manderbacka K: Examining what self-rated health question is understood to mean by respondents. Scand J Soc Med 1998, 26:145-153.

17. World Health Organization: International Classification of Functioning, Disability and Health: ICF. Geneva: WHO; 2001.

18. Maierhofer S, Almazan-Isla J, Alcalde-Cabero E, de Pedro-Cuesta J: Prevalence and features of ICF-disability in Spain as captured by the 2008 National Disability Survey. BMC Public Health 2011, 11:897.

19. Reise SP, Morizot J, Hays RD: The role of the bifactor model in resolving dimensionality issues in health outcomes measures. Qual Life Res 2007, 16(Suppl 1):19-31.

20. Jennrich Rl, Bentler PM: Exploratory Bi-factor analysis. Psychometrika 2011, 76:537-549

21. Reeve BB, Fayers $P$ : Applying item response theory modeling for evaluating questionnaire item and scale properties. In Assessing Quality of Life in Clinical Trials: Methods of Practice. 2nd edition. New York: Oxford University Press; 2005:55-73.

22. Pallant JF, Tennant A: An introduction to the Rasch measurement model: an example using the Hospital Anxiety and Depression Scale (HADS). Br J Clin Psychol 2007, 46:1-18.

23. Reeve BB, Hays RD, Bjorner JB, Cook KF, Crane PK, Teresi JA, Thissen D, Revicki DA, Weiss DJ, Hambleton RK, Liu H, Gershon R, Reise SP, Lai JS, Cella D, PROMIS Cooperative Group: Psychometric evaluation and calibration of health-related quality of life item banks: plans for the Patient-Reported Outcomes Measurement Information System (PROMIS). Med Care 2007, 45(Suppl 1):S22-S31.

24. Samejima F: Estimation of latent ability using a response pattern of graded scores. Psychometrika Monogr Supp/ 1969, 17:334.

25. Choi SW, Gibbons LE, Crane PK: Lordif: an R package for detecting differential item functioning using iterative hybrid ordinal logistic regression/item response theory and Monte Carlo simulations. J Stat Softw 2011, 39:1-30.

26. Camilli G, Shepard LA: Methods for Identifying Biased Test Items. Thousand Oaks, CA: SAGE Publications; 1994

27. Strobl C, Boulesteix AL, Kneib T, Augustin T, Zeileis A: Conditional variable importance for random forests. BMC Bioinforma 2008, 9:307.

28. R Development Core Team: R: a language and environment for statistical computing. [http://www.R-project.org]

29. Smith AM, Shelley JM, Dennerstein L: Self-rated health: biological continuum or social discontinuity? Soc Sci Med 1994, 39:77-83.

30. Jylhä M: What is self-rated health and why does it predict mortality? Towards a unified conceptual model. Soc Sci Med 2009, 69:307-316.

31. Keller SD, Ware JE Jr, Bentler PM, Aaronson NK, Alonso J, Apolone G, Bjorner JB, Brazier J, Bullinger M, Kaasa S, Leplège A, Sullivan M, Gandek B: Use of structural equation modeling to test the construct validity of the SF-36 Health Survey in ten countries: results from the IQOLA Project. International Quality of Life Assessment. J Clin Epidemiol 1998, 51:1179-1188.

32. Hambleton RK, Swaminathan $\mathrm{H}$, Rogers $\mathrm{HJ}$ : Fundamentals of item response theory. Newbury Park, CA: Sage; 1991.

33. Prieto-Flores ME, Fernandez-Mayoralas G, Rojo-Perez F, Lardiés-Bosque R, Rodríguez-Rodríguez V, Ahmed-Mohamed K, Rojo-Abuín JM: Factores sociodemográficos y de salud en el bienestar emocional como dominio de calidad de vida de las personas mayores en la Comunidad de Madrid.
2005 (Sociodemographic and health factors explaining emotional wellbeing as a quality of life domain of older people in Madrid, Spain. 2005). Rev Esp Salud Publica 2008, 82:301-313.

34. Fylkesnes $\mathrm{K}$, Førde $\mathrm{OH}$ : The Troms $\varnothing$ study: predictors of self-evaluated health-has society adopted the expanded health concept? Soc Sci Med 1991, 32:141-146.

doi:10.1186/1471-2458-14-189

Cite this article as: Bostan et al:: Biological health or lived health: which predicts self-reported general health better? BMC Public Health 2014 14:189.

\section{Submit your next manuscript to BioMed Central and take full advantage of:}

- Convenient online submission

- Thorough peer review

- No space constraints or color figure charges

- Immediate publication on acceptance

- Inclusion in PubMed, CAS, Scopus and Google Scholar

- Research which is freely available for redistribution

Submit your manuscript at www.biomedcentral.com/submit
C) Biomed Central 